Invited Review

\title{
Leptospirosis in Sri Lanka
}

\author{
JN Warnasekara ${ }^{1}$, SB Agampodi ${ }^{1}$ \\ Sri Lankan Journal of Infectious Diseases 2017 Vol.7 (2):67-75 \\ DOI: http://dx.doi.org/10.4038/sljid.v7i2.8155
}

\begin{abstract}
Leptospirosis has become one of the most important infectious diseases in Sri Lanka over the last few years. Though it was well documented and investigated in the 1960's and 70's, the disease was mostly forgotten for more than 30 years. Leptospirosis has not been among the diseases under scientific investigation in Sri Lanka even after an outbreak in 2003. However, it has become a priority research area following a large outbreak of leptospirosis in 2008 with more than 7000 reported cases.
\end{abstract}

Leptospirosis is endemic in all but one district in Sri Lanka. Reported cases are mostly males and different occupational categories are listed as risk groups. The commonest exposure risk is for people engaged in farming or with exposure in paddy fields. The case fatality ratio varies between $2-3 \%$ in all cases, whereas it may be as high as $33 \%$ in complicated cases.

Thirteen different strains of Leptospira in five species have been isolated from human cases from Sri Lanka and 10 serogroups have been reported. Diagnosis is a major challenge faced by the treating physicians and further studies are required to understand the clinicopathology of disease.

Keywords: Leptospirosis, Sri Lanka

\section{Introduction}

Leptospirosis is a zoonotic disease caused by a group of spirochetes belonging to the genus Leptospira and family Leptospiraceae. ${ }^{1}$ The genotypic classification of leptopiraceae shows 21 different species of which 9 are pathogenic species causing human disease. In addition to these pathogenic species, 6 intermediate species of Leptospira can also cause human disease, though they are primarily soil living. ${ }^{2}$ The traditional classification of Leptospira include more than 250 serovars based on the serological classification. $^{2}$

Leptospirosis is a historical disease and a large number of different names have been used in different countries. Stuttgart Disease, Mud Fever, Rice-Field Fever, Cane-

${ }^{1}$ Department of Community Medicine, Faculty of Medicine and Allied Sciences, Rajarata University of Sri Lanka

Address for correspondence: Prof Suneth Agampodi, Department of Community Medicine, Faculty of Medicine and Allied Sciences, Rajarata University of Sri Lanka Tele : +094 777880096

Email: sunethagampodi@yahoo.com

(iD https://orcid.org/0000-0001-7810-1774

Received 2 October 2017 and accepted 8 October 2017 
Cutter Fever, Swineherd's Disease, Canicola Fever are some of these names used in other countries. ${ }^{1}$

In documented history, leptospirosis was first investigated in Sri Lanka among captured rodents in Colombo in 1953. Rajasuriya, Somasundaram and Nagaratnam reported the first confirmed cases of leptospirosis in Sri Lanka from Colombo and Batticaloa in $1959 .{ }^{3}$ Cases were diagnosed by serology using the complement fixation test; two cases were positive for Leptospira icterohaemorrhagiae at a titre of 1/400, and the other had seroconversion from $1 / 50$ to $1 / 100$ for paired sera. Guinea pig inoculation of patients' urine was done and live leptospira were demonstrated in all three animals. Since then, leptospirosis was described in Sri Lanka as a common cause of febrile illnesses, mainly from the wet region. It was made a notifiable disease in Sri Lanka in 1991.

\section{Incidence}

Disease notification data from 1991 shows a steady increase of reporting of leptospirosis until 2007. ${ }^{4}$ This was mainly attributed to improved surveillance. However, the outbreak of leptospirosis in 2003 created an alert among health professionals on leptospirosis as an emerging disease. In 2007, clustering of unidentified fever cases and a few deaths were reported from Matara, Gampaha and Kandy districts, some of whom were confirmed as leptospirosis. In 2008, Sri Lanka experienced the largest documented outbreak of leptospirosis in Sri Lanka with an estimated incidence of 371/100000. ${ }^{5}$ However, incidence based on notification data may be a gross underestimation of the true problem as it has been shown that the reported data might be showing only around $30 \%$ of the actual caseload. ${ }^{6}$ Since 2008 , the number of cases reported has been more than 3000 per year and global comparison data shows Sri Lanka as the country with the highest incidence of leptospirosis. ${ }^{4}$

\section{Geographical distribution}

Studies on geographical distribution of leptospirosis are scarce in Sri Lanka. Most of the studies done were based on patients admitted to a single hospital. First confirmed cases of the disease were reported from Colombo (three cases) and Batticaloa (one case). ${ }^{3}$ Since then, confirmed series of cases were reported from General Hospital Colombo, ${ }^{7,8,9}$ General Hospital, Ragama, ${ }^{10}$ Peripheral Hospital, Kegalle (present District General Hospital, Kegalle) ${ }^{11}$ and Peripheral Hospital, Ratnapura (present District General Hospital, Ratnapura).$^{12}$ Geographic distribution of confirmed cases based on samples received for confirmation was analysed by Nityananda in 1967, ${ }^{13}$ which showed that the districts of Colombo, Kalutara, Gampaha, Ratnapura, Galle, Badulla, and Kurunegala had confirmed cases between 1962 and 1964. Based on disease surveillance data until 2008, the Epidemiological Unit, Sri Lanka concluded that there are eight leptospirosis endemic districts in Sri Lanka, although all the other districts too report cases throughout the year. These eight districts include Colombo, Kalutara, Gampaha, Ratnapura, Galle, Matara, Kegalle, Matale and Kurunegala. However, notification data after 2008 show that cases are reported from all districts with outbreaks reported from new areas each year. The combined case distribution map (Figure 1) shows that only Jaffna is not reporting large number of cases of 
leptospirosis, while all the other districts are having outbreaks or unexpected increase of case numbers.

\section{Sero-prevalence of Leptospira antibodies in humans}

The first Sri Lankan study on sero-prevalence of leptospirosis was undertaken in 1962. ${ }^{7}$ The study included the high-risk population along the Colombo-NegomboPuttalam canal and high-risk groups among the farming population. Prevalence of Leptospira antibodies was reported as high as $23.8 \%$ in this study sample. Babuderi and Jagels (1962) ${ }^{13}$ reanalysed some of these samples, using a panel of serovars and found that sero-prevalence of leptospirosis among 51 sera samples from healthy individuals were $17.7 \%$. Sero-prevalence of leptospirosis among serum samples taken from suspected typhoid and paratyphoid patients was studied at the MRI during the period 1962-1964. ${ }^{14}$ This study found that 62 of $1475(4.1 \%)$ samples were positive by the leptoagglutination test. However, interpretation of this data is complicated, as seropositivity could be either due to co-infection or previous infection. Seroprevalence of Leptospira antibodies had been studied in occupational groups in 1967. ${ }^{14}$ Testing was done using macroscopic agglutination test (reported as Galton's macroslide agglutination test). This study showed seropositivity ( $\geq$ titre of $1 / 30$ ) in different occupational groups as shown in Table 1.

Spatial Distribution of Leptospirosis 2008-15

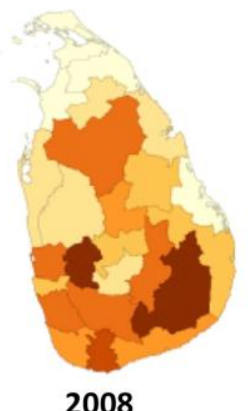

2008

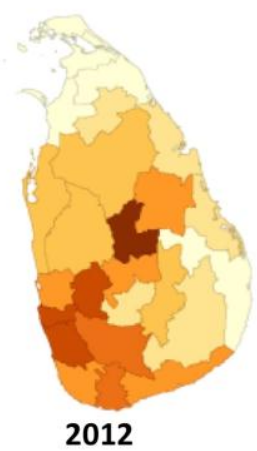

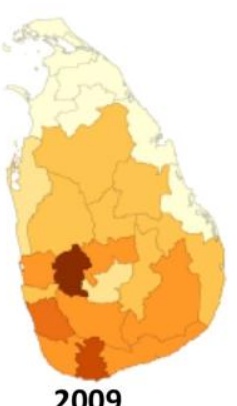

2009

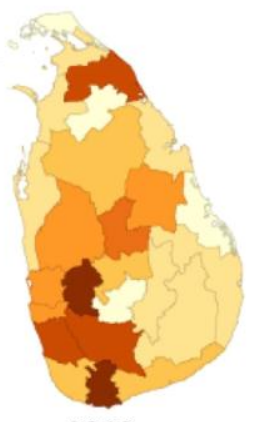

2013

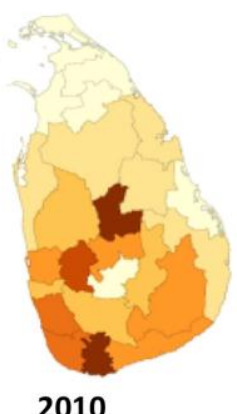

2010

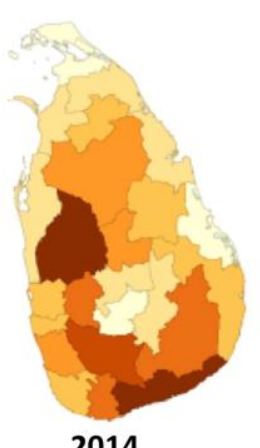

2014
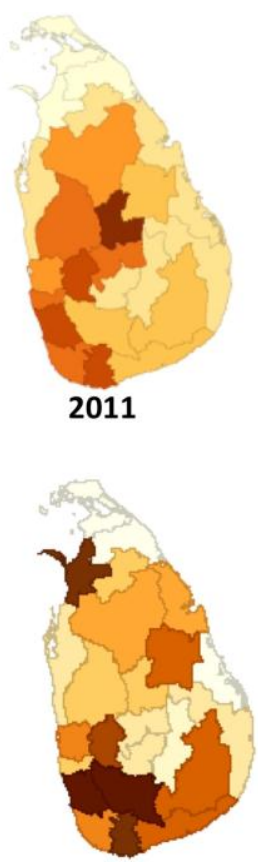

2015

Figure 1: Case density of reported leptospirosis in Sri Lanka.

(Dark areas shows higher incidence. Map created using natural breaks in GeoDa. Similar colour areas in different years shows different incidence. Colour intensity is relative to the given year only) 
Table 1: Seropositivity ( $\geq$ titre of $1 / 30$ ) according to occupational exposure ${ }^{13}$

\begin{tabular}{lccc}
\hline Occupational/recreational exposure & $\begin{array}{c}\text { No } \\
\text { tested }\end{array}$ & $\begin{array}{c}\text { No } \\
\text { positive }\end{array}$ & $\%$ \\
\hline sewer workers & 51 & 8 & 15.7 \\
workers in coconut plantations & 140 & 32 & 22.9 \\
workers in rice fields & 109 & 22 & 20.2 \\
workers in sugar cane fields & 11 & 8 & 72.7 \\
workers in animal farms & 32 & 0 & 0.0 \\
workers in abattoirs & 46 & 16 & 34.8 \\
workers in fish markets & 34 & 16 & 47.1 \\
scavengers & 38 & 3 & 7.9 \\
bathing in Kalu ganga & 45 & 17 & 37.8 \\
\hline
\end{tabular}

These entire risk groups showed high seropositivity but the positive criteria were different from previously published studies. ${ }^{7,8,9,10,11}$ However, seroprevalence studies are not available from more recent literature.

\section{Disease causing agent}

The aetiological agents causing leptospirosis in Sri Lanka were fully reviewed in 2016. ${ }^{15}$ Thirteen different strains of Leptospira have been isolated from human cases from Sri Lanka (Table 2).

Table 2: Summary of Sri Lankan isolates from human cases ${ }^{15}$

\begin{tabular}{|c|c|c|}
\hline Serovar & $\begin{array}{l}\text { First } \\
\text { isolated/ } \\
\text { reported }\end{array}$ & Source \\
\hline $\begin{array}{l}\text { L. interrogans serovar } \\
\text { Icterohaemorragiae }\end{array}$ & 1961 & From a 46 years old male from Sri Lanka \\
\hline $\begin{array}{l}\text { L. borgpetersenii serovar } \\
\text { Ceylonica }^{1}\end{array}$ & 1964 & Strain Piyasena. From a male baker from Colombo. \\
\hline $\begin{array}{l}\text { L. interrogans serovar } \\
\text { Geyaweera }\end{array}$ & 1965 & Strain Geyaweera. From a patient from Sri Lanka. \\
\hline $\begin{array}{l}\text { L. interrogans serovar } \\
\text { Weerasinghe }\end{array}$ & 1965-66 & Strain Weerasinghe. Human case described in 1971. \\
\hline $\begin{array}{l}\text { L. kirschneri serovar } \\
\text { Ratnapura }\end{array}$ & 1965-66 & $\begin{array}{l}\text { Strain Wumalasena. From a patient from Ratnapura and } \\
\text { reported in } 1970\end{array}$ \\
\hline $\begin{array}{l}\text { L. interrogans serovar } \\
\text { Gem }\end{array}$ & 1966 & Strain Simon. From a human case \\
\hline $\begin{array}{l}\text { L. santarosai serovar } \\
\text { Alice }\end{array}$ & 1966 & Srain Alice, From a human case from Ratnapura \\
\hline $\begin{array}{l}\text { L. interrogans serovar } \\
\text { Lanka }\end{array}$ & 1967 & Strain R 740. Isolated from a patient from Ratnapura \\
\hline $\begin{array}{l}\text { L. kirschneri serovar } \\
\text { Grippotyphosa }\end{array}$ & 1967 & From a human case from Ratnapura, Sri Lanka \\
\hline $\begin{array}{l}\text { L. interrogans serovar } \\
\text { Bangkinang }\end{array}$ & 1971 & Human case (details not available) \\
\hline $\begin{array}{l}\text { L. interrogans serovar } \\
\text { Bulgarcia }\end{array}$ & 1971 & Human case (details not available) \\
\hline $\begin{array}{l}\text { L. interrogans serovar } \\
\text { Ricardi }\end{array}$ & 1971 & Human case (details not available) \\
\hline $\begin{array}{l}\text { L. interrogans serovar } \\
\text { Pyrogenes }\end{array}$ & $1971-73$ & Human case from Ragama, Sri Lanka \\
\hline
\end{tabular}


Of these, five serovars were first identified from Sri Lanka. Eight of these isolates are used as the "typing strain" (the typical strain representing the particular serovar in typing of new cultures) in scientific studies globally. The same paper reported that Leptospira from 10 serogroups, Icterohaemorragiae, Autumnalis, Sejroe, Grippotyphosa, Javanica, Louisiana, Canicola , Hebdomadis, Pomona and Pyrogenes have been isolated from Sri Lanka. Recent molecular based studies showed human disease from four species of Leptospira; L. interrogans, L. kirschneri, $L$. borgpetersenii and L.weilli. ${ }^{15}$

\section{Clinical spectrum and complications}

Leptospirosis can vary from mild self-limiting fever to a severe disease with multisystem involvement, as a result of which it is difficult to determine its true incidence. ${ }^{16}$ Meretic et al (1961) in an early report from Sri Lanka, described 45 laboratory confirmed cases of leptospirosis in 272 patients with pyrexia of unknown origin from Colombo and Negombo. ${ }^{8}$ This was the first description of mild cases of leptospirosis in Sri Lanka.

Liver and kidney involvement was first described on 1959 by Rajasuriya et al. ${ }^{3}$ A study done in 1964 reported 10 patients with delirium and coma, 7 patients with acute renal failure, 9 patients with haemorrhagic manifestations, 22 patients with pneumonitis, 8 patients with hypotension and 1 patient with myocarditis. ${ }^{9}$ N.J. Herath et al reported a case series of acute pancreatitis in patients confirmed to have leptospirosis. ${ }^{17}$ These complications and spectrum of disease appears to vary by geographical area. Micro geographical variation of causative organisms adapted to different environmental factors could be one probable explanation for the diverse clinical features of patients presenting in different areas of Sri Lanka. ${ }^{18}$

\section{Recent outbreaks of Leptospirosis}

Even though Leptospirosis had been named as a notifiable disease in 1991, it was considered as a priority health issue in Sri Lanka only after the largest ever outbreak

Table 3 Leptospirosis cases based on Quarterly Epidemiological Report data. ${ }^{19}$

\begin{tabular}{ll}
\hline Year & $\begin{array}{l}\text { Notified } \\
\text { cases }\end{array}$ \\
\hline 2004 & 2243 \\
2005 & 1147 \\
2006 & 1550 \\
2007 & 2198 \\
2008 & 7421 \\
2009 & 6610 \\
2010 & 4554 \\
2011 & 6689 \\
2012 & 3690 \\
2013 & 4308 \\
2014 & 3235 \\
2015 & 4435 \\
\hline
\end{tabular}

in 2008. ${ }^{19}$ Notification data from the epidemiology unit (Table 3) shows that there is an overall increase of notifications till 2008 and then more than 3000 cases each year.

\section{Leptospirosis case fatality ratio (CFR)}

The largest outbreak from 2008 to 2016 was reported in year 2008 with 7421 cases and 207 deaths. The case fatality ratio was $2.7 \% .^{20}$ These cases were based on reported cases of leptospirosis through the 
surveillance system.

A study done in National Hospital of Sri Lanka showed that 15 of the 45 diagnosed patients treated at Intensive Care Unit died due to leptospirosis (CFR-33.3\%). ${ }^{21}$ This is the highest reported CFR among patients with severe leptospirosis. During the 2008 outbreak 33 of 227 patients with severe leptospirosis died at Teaching Hospital Peradeniya. ${ }^{22}$ There are very few reports of hospital based studies to assess the true disease burden including mild cases. A study done in Matale, Kandy and Kegalle hospitals parallel to the 2008 outbreak reported 7 deaths from 232 confirmed cases of leptospirosis. The case fatality rate was $3 \%$, which was almost similar to the national data. Another study done in the National Hospital, Sri Lanka reported 3 deaths out of 370 confirmed cases of leptospirosis. The CFR was $1.9 \%$. These were the only two studies published in the Sri Lankan literature which included mild cases. The actual disease burden is therefore probably grossly underestimated due to non-inclusion of mild cases.

\section{Diagnosis of leptospirosis}

Despite many trials conducted all around the world, there is no single diagnostic test for leptospirosis with high positive and negative predictive values. Although Sri Lankan publications based on culture isolation and immunological diagnostic methods are available from 1957 to 1977, there was a long silent period for publications from 1977 until 2007.

The first culture isolation in a Sri Lankan patient was reported in $1959 .{ }^{3}$ There were a total of 8 publications based on culture isolation, of which the last publication was in 1976. ${ }^{7,14,23,24}$ Publications based on Leptospira agglutination lysis test was reported since 1959. ${ }^{8}$ The first publication based on Microscopic Agglutination Test (MAT) was published in 1976. ${ }^{24}$ Molecular diagnostic methods has directed leptospirosis research in Sri Lanka to a novel era. The first PCR based publication was by Koizumi et al in 2009. ${ }^{24}$

Microscopic Agglutination Test (MAT) is considered the gold standard and the Medical Research Institute of Sri Lanka continues to perform MAT for the whole country. However, many researchers have shown that MAT can no longer be used as the gold standard test. ${ }^{26,27}$ A diagnostic sensitivity of $51 \%$ using q PCR technique was shown in 2011. ${ }^{28}$ The IgM-ELISA and Immunochromatographic based tests have shown similar sensitivity in the acute phase of the disease when compared with MAT. ${ }^{26}$ Denipitiya et al (2016) demonstrated a sensitivity of $67.7 \%$ using rt-PCR (a RNA based technology) to detect Leptospira in blood suggesting that this test has the potential to facilitate rapid diagnosis. ${ }^{29}$

\section{Challenges and future research}

Prevention and control of leptospirosis is a challenge, not only in Sri Lanka, but also in other countries. Even though the Sri Lankan national programme uses chemoprophylaxis ${ }^{30}$, this strategy is not evidence based. Two Cochrane reviews done in year $2000^{31}$ and updated in $2010^{32}$ clearly show that there is no evidence to suggest that chemoprophylaxis with doxycycline is effective in preventing primary infection. 
Although Sri Lankan research in leptospirosis is increasing, there are still many challenges faced by both clinicians and researchers. ${ }^{33}$ Despite being one of the most important public health issues in Sri Lanka, diagnostic facilities are not routinely available to clinicians. Research on clinical management is scarce and further studies supported by basic science studies are needed to understand the clinicopathology of this disease. Immunopathology of changing disease, especially with a changing clinical profile also needs to be explored in local settings.

\section{References}

1. Faine, S., Adler, B., Bolin, C. Perolat, P. Leptospira and Leptospirosis. 2nd ed. MediSci, Melbourne, Vic. Australia; 1999. No doi

2. Adler B. Leptospira and Leptospirosis. 3rd ed. Adler B, editor. Springer Heidelberg New York Dordrecht London; 2015. doi :10.1007/978-3-662-45059-8

3. Rajasuriya K, Somasunderam M, Nagaratnam N. Leptospirosis in Ceylon. $J$ Trop Med Hyg 1959; 62:205-10. No doi

4. Agampodi, S, Peacock SJ., Thevanesam V. "The potential emergence of leptospirosis in Sri Lanka." The Lancet Infectious Diseases 2009; 9:524-526. doi : http://dx.doi.org/10.1016/S1473-3099(09)70211-7

5. Epidemiology Unit, Leptospirosis Surveillance Report, Quarterly Epidemiological Report. 2008 (3); No doi

6. Cassadou S, Rosine J, Flamand C, et al. Underestimation of leptospirosis Incidence in the French West Indies. PLoS Negl Trop Dis. 2016; 10(4):e0004668. doi 10.1371/journal.pntd.0004668

7. Babudieri B, Jagels G. Serological research on the presence of leptospirosis in Ceylon. Ceylon Med J. 1962; 7:213-4. No doi

8. Maretic Z, Arumanayagam P, Nithyananda K, et al.. Investigation of pyrexias of unknown origin in Ceylon. A preliminary report. Ceylon Med J. 1962; 7:8994. No doi

9. Rajasuriya K, Munasinghe DR, Vitarne UT, et al. Leptospirosis in Ceylon: a clinical study. Ceylon Med J. 1964; 9:136-53. No doi

10. Walloopillai, NJ., Markus HKNI., Nityananda K.. Leptospirosis in Ceylon. Ceylon Medical Journal 1966; 11(2):50-8. No doi

11. Nagaratnam N, Weerasinghe WM, Fernandopulle M. Leptosiprosis (anicteric) as a cause of long and short term pyrexia in the Kegalla district (Ceylon). Ceylon Med J. 1967; 12(4):225-8. No doi

12. Thirunavukkarasu K, De Silva VN, Amarasinghe G. Leptospirosis in Ceylonese children. Ceylon Med J 1967; 12(4):202-5. No doi

13. Babudeiri B, Jagels G. Serological research on the presence of leptospirosis in Ceylon. Ceylon Med J 1962; 1964(93):136-53. No doi

14 Nityananda K. Leptospirosis:serological survey of occupational groups in Ceylon. J Trop Med Hyg 1967; 70(10):250-4. No doi

15 Naotunna C, Agampodi SB, Agampodi TC. Etiological agents causing leptospirosis in Sri Lanka: A review. Asian Pacific Journal of Tropical Medicine. 2016; 9:390-4. doi 10.1016/j.apjtm.2016.03.009

16 Cassadou S, Rosine J, Flamand C, et al. Underestimation of leptospirosis incidence in the French West Indies. PLoS Negl Trop Dis. 2016; 10(4):e0004668. doi 10.1371/journal.pntd.0004668

17. Herath NJ, Kamburapola CJ, Agampodi SB. Severe leptospirosis and pancreatitis; A case series from a leptospirosis outbreak in Anuradhapura 
district, Sri Lanka. BMC Infect Dis. 2016; 16(1):644. doi 10.1186/s12879-0162010-4

18. Agampodi SB, Dahanayaka NJ, Bandaranayaka AK, et al. Regional differences of leptospirosis in Sri Lanka: Observations from a floodassociated outbreak in 2011. PLoS Negl Trop Dis. 2014; 8(1):22. doi 10.1371/journal.pntd.0002626

19. Agampodi SB, Peacock SJ, Thevanesam V, et al. Leptospirosis outbreak in Sri Lanka in 2008: lessons for assessing the global burden of disease. Am J Trop Med Hyg 2011; 85(3):471-8. doi:10.4269/ajtmh.2011.11-0276

20. Epidemiology Unit - Sri Lanka. Surveillance report on Leptospirosis. Quarterly Epidemiological Bulletin.2008; $3^{\text {rd }}$ quarter ; No doi

21. Gunawardhana SACU, Sellahewa KH. Clinical features of leptospirosis: a prospective descriptive study at the National Hospital of Sri Lanka (NHSL) in 2007. Ceylon Med J. 2008; 53(4):155-6. No doi

22. Kularatne SAM, Budagoda BDSS, de Alwis VKD, et al. High efficacy of bolus methylprednisolone in severe leptospirosis: a descriptive study in Sri Lanka.

Postgrad Med J. 2011; 87(1023):13-7. doi : 10.1136/pgmj.2009.092734

23. Nityananda K, Sulzer CR. A new serotype of Leptospira belonging to the autumnalis serogroup. J Trop Med Hyg. 1971; 74(8):184-6. No doi

24. Ramachandran S, Rajapakse CN, Perera M V, Yoganathan M. Patterns of acute renal failure in leptospirosis. J Trop Med Hyg 1976; 79(7):158-60.

No doi

25. Koizumi N, Gamage CD, Muto M, et al. Serological and genetic analysis of leptospirosis in patients with acute febrile illness in Kandy, Sri Lanka. Jpn J Infect Dis. 2009; 62(6):474-5. No doi

26. Niloofa R, Fernando N, de Silva NL, et al. Diagnosis of leptospirosis: Comparison between Microscopic Agglutination Test, IgM-ELISA and IgM Rapid Immunochromatography Test. PLoS One. 2015; 10(6):e0129236. doi 10.1371/journal.pone.0129236

27. Agampodi SB, Dahanayaka NJ, Nockler K, et al.. Redefining Gold standard testing for diagnosing leptospirosis: Further evidence from a wellcharacterized, flood-Related Outbreak in Sri Lanka. Am J Trop Med Hyg 2016; 16:16-33. doi: 10.4269/ajtmh.16-0033

28. Agampodi SB, Matthias MA, Moreno AC, Vinetz JM. Utility of quantitative polymerase chain reaction in leptospirosis diagnosis: association of level of leptospiremia and clinical manifestations in Sri Lanka. Clin Infect Dis 2012; 10; 54(9):1249-55. doi : 10.1093/cid/cis035

29. Denipitiya DTH, Chandrasekharan NV, Abeyewickreme W, et al. Application of a real time Polymerase Chain Reaction (PCR) assay for the early diagnosis of human leptospirosis in Sri Lanka. Biologicals 2016; 44(6):497-502. doi : http://dx.doi.org/10.1016/j.biologicals.2016.09.004

30. Epidemiology Unit, Re:Prevention and Control of Leptospirosis, Circular No.01-31/2008, 2008. Available at http://www.epid.gov.lk/web/attachments/article/179/epid35122008_eng.pdf

31. Guidugli, Fábio, Aldemar A. Castro, and Álvaro N. Atallah. "Antibiotics for preventing leptospirosis." The Cochrane Library. 2000(4):CD001305. doi : 10.1002/14651858.CD001305

32. Brett- Major, David M., and Robert J. Lipnick. "Antibiotic prophylaxis for leptospirosis." The Cochrane Library 2009; 8(3):CD007342 
doi : 10.1002/14651858.CD007342.pub2.

33. Agampodi, Suneth, Buddhika Wijerathne, and Kosala Weerakoon. "Situation of Sri Lanka, where autochthonous malaria is no longer a problem, and other infections dominate, such as dengue, leptospirosis and rickettsioses." Current Opinion in Infectious Diseases 2016; 29(5):446-452.

doi : 10.1097/QCO.0000000000000303 